\title{
Random Fatigue Analysis of Drill-Strings in Frequency Domain
}

\author{
JiaHao Zheng ${ }^{1}$, Jianming Yang ${ }^{1}$, Ping Yang ${ }^{2}$ \\ ${ }^{1}$ Department of Mechanical Engineering, Memorial University of Newfoundland, A1B 3X5, St John's Canada \\ ${ }^{2}$ School of Mechanical Engineering, Jiangsu University, 212013, Zhenjiang, Jiangsu, P.R.China,
}

\begin{abstract}
Predicting fatigue damage induced by vibrations is of benefit to oil and gas industry. In this paper a spectral method is developed to estimate the damage of vibration, including both deterministic and random vibration, on the fatigue life of drillstrings. The drill-string is first modeled by the continuous parameter method with two vibration modes: axial and torsional. After the vibration response is obtained, the equivalent stress spectra are calculated for any position along the drill-string, based on maximum shear stress fatigue failure criterion. The fatigue life of the drill-string at arbitrary position is then estimated by the developed spectral methods
\end{abstract}

\section{Introduction}

A drill-string is a slender structure used in the oil and gas industry. Fatigue of drill-string is a critical issue faced by the industry, and rich research works have dealt this research topic. These works can be roughly divided into two categories: experimental and theoretical. Bachman[1] investigated the fatigue of full-size drill-pipes experimentally with the drill-pipes clamped as cantilevered beams and subjected to rotational bending. However, he did not consider the axial load to the drillpipes, and the test was conducted only in the condition of air. Morgan and Robin [2] reported their testing results from small-scale coupons cut from as-produced seamless hot rolled drill pipes. Axial load was applied to the specimens to gain more realistic data. In 1991, Grondin and Kulak [3] conducted experiments using full-size drill pipes subjected to axial load, fluctuating bending and rotating in both air and corrosive media. Their tests provided the most comprehensive data so far for drillstring fatigue. In addition to the experimental works, researchers developed various theoretical methods for drill-string fatigue calculation. The theoretical work has been mainly conducted along two lines. One is based on the fracture mechanics theory [4]. These methods assume micro cracks exist in the drill pipe materials. These micro cracks propagate in the drill pipe body along certain directions under cyclic loadings, and eventually develop into fractures [5] which lead to fatigue failures. The other combines the fatigue $\mathrm{S}-\mathrm{N}$ relation with the linear damage cumulative law to compute an equivalent damage. One of the most representative work along this line was by Lubinski [6], in which the fatigue damage induced by the dog-legs was calculated. Thereafter, modifications were made to the S-N relation and boundary conditions by Hansford and Lubinski[7], $\mathrm{Wu}[8,9]$ and other researchers to improve the accuracy of the prediction. In real drilling operation, vibration is a important factor causing fatigue. Further the vibration is more likely random. However, in the existing literature, the vibration effect was rarely considered. Patel and Vaz's work [10] seems the only one accounting for the contribution of vibration to the fatigue of drill-string. In this work, the vibration was considered as periodical and the random nature was not considered. This paper, using spectral method [12], investigates the effect of axial and torsional vibrations on the fatigue LIFE of drill strings. The vibrations are examined with consideration of the randomness. It is organized as follows: section 1 gives a background review on the research of drill-string fatigue. In section 2, continuous vibration models of the drill-string are developed. Section 3 presents the stress transformation and the determination stress spectrum. Following that spectral method for fatigue prediction is presented in section 4. Simulation examples and result analysis are given in the following two sections. The last section concludes the whole paper.

\section{Vibration model}

Given the similarity between the axial and torsional vibrations, only axial mode is presented in detail below. The torsional part can be easily derived following the steps in the axial vibration. A model of the drill-string under axial vibration is shown in Fig. 1. Let $\mathrm{x}$ denote the axial position. And $x=0$ is set to be at the bottom of the drill-string. The axial vibration of the drill-string is expressed as:

$$
\begin{gathered}
A_{i} E \frac{\partial^{2} \widetilde{u}_{i}(x, t)}{\partial x^{2}}-\gamma_{i} \frac{\partial \widetilde{u}_{i}(x, t)}{\partial t}-\rho A_{i} \frac{\partial^{2} \widetilde{u}_{i}(x, t)}{\partial t^{2}}- \\
\left(\rho-\rho_{m}\right) g A_{i}=0(1)
\end{gathered}
$$


where $\rho ; E$ are the material's density and Young's modulus. $\gamma_{\mathrm{i}}$ denotes the viscous damping coefficient and $A_{i}$ represents the cross section area. $i=1,2$ stands for the drill-pipe and the drill-collar section respectively.

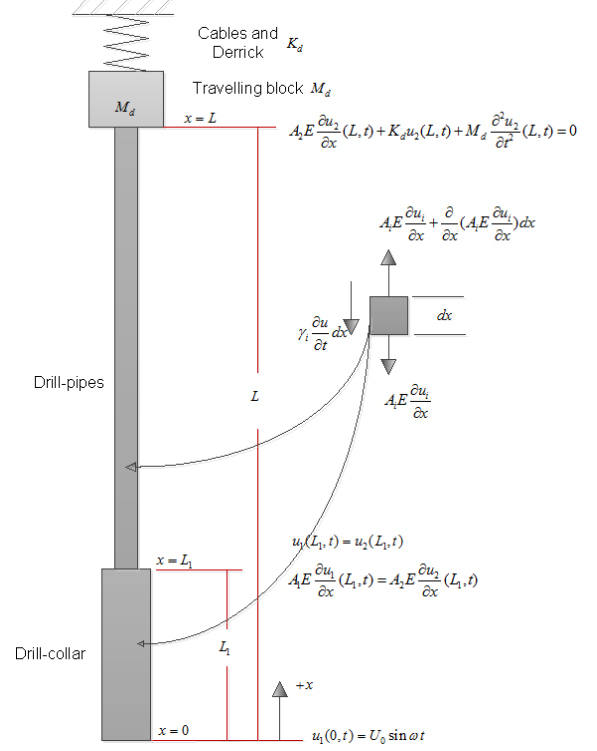

Figure 1. Schematic of a drill-string.

$\tilde{\mathrm{u}}_{\mathrm{i}}(\mathrm{x}, \mathrm{t})$ denotes the elastic displacement in axial direction, which includes static and dynamic parts: $\tilde{u}_{\mathrm{i}}(\mathrm{x}, \mathrm{t})=\mathrm{u}_{\mathrm{is}}(\mathrm{x})+\mathrm{u}_{\mathrm{i}}(\mathrm{x}, \mathrm{t})$. Substituting this equation into Eq. 1 reduces it into

$$
A_{i} E \frac{\partial^{2} u_{i}(x, t)}{\partial x^{2}}-\gamma_{i} \frac{\partial u_{i}(x, t)}{\partial t}-\rho A_{i} \frac{\partial^{2} u_{i}(x, t)}{\partial t^{2}}=0(2)
$$

The excitation is assumed from the base motion, represented by $\mathrm{u}_{\mathrm{b}}(\mathrm{t})$, at the bottom of the drill-string caused by the unevenness of the bottom. Then Eq. 2 becomes

$$
\begin{aligned}
& A_{i} E \frac{\partial^{2}}{\partial x^{2}}\left[u_{i}(x, t)-u_{b}(t)\right]-\gamma_{i} \frac{\partial u_{i}(x, t)}{\partial t} \\
& -\rho A_{i} \frac{\partial^{2} u_{i}(x, t)}{\partial t^{2}}=0
\end{aligned}
$$

By defining the axial displacement relative to the base as $v(x, t)=u(x, t)-u_{b}(t)$, we get:

$$
\begin{array}{r}
\frac{\partial u}{\partial t}=\frac{\partial v}{\partial t}+\frac{\partial u_{b}}{\partial t} \\
\frac{\partial^{2} u}{\partial t^{2}}=\frac{\partial^{2} v}{\partial t^{2}}+\frac{\partial^{2} u_{b}}{\partial t^{2}}
\end{array}
$$

Inserting the above two equations into Eq. 3 leads to

$$
\begin{aligned}
& \rho A_{i} \frac{\partial^{2} v_{i}}{\partial t^{2}}+\gamma_{i} \frac{\partial v_{i}}{\partial t}-A_{i} E \frac{\partial^{2} v_{i}}{\partial x^{2}} \\
&=-\gamma_{i} \frac{\partial u_{b}}{\partial t}-A_{i} \frac{\partial^{2} u_{b}}{\partial t^{2}}
\end{aligned}
$$

The right-hand side of this equation represents excitation induced by the base motion. It can be expressed as

$$
u_{b}(t)=p(t)+w(t)
$$

where $\mathrm{p}(\mathrm{t})$ and $\mathrm{w}(\mathrm{t})$ represent the deterministic base motion and random base motion, respectively.

Solution to the equation can be written in the following form using the Galerkinmethod[14]:

$$
v(x, t) \approx \sum_{n=1}^{R} X_{n}(x) p_{n}(t)
$$

where $\mathrm{R}$ stands for the order to be retained in the discretization.pn(t) are the generalized coordinates. $\mathrm{Xn}(\mathrm{x})$ are the appropriatebasis functions satisfying the specific boundary conditions. The boundary conditions at the top, the interface betweendrill-pipe and drill-collar and the bottom are presented as (SeeFig. 1):

The Top: $2 E \frac{\partial u_{2}}{\partial x}(L, t)+K_{d} u_{2}(L, t)+M_{d} \frac{\partial^{2} u_{2}}{\partial t^{2}}=0$

The interface: $A_{1} E \frac{\partial u_{1}}{\partial x}\left(L_{1}, t\right)=A_{2} E \frac{\partial u_{2}}{\partial x}\left(L_{1}, t\right)$;

The bottom: $u_{1}(0, t)=0$

$$
u_{1}\left(L_{1}, t\right)=u_{2}\left(L_{1}, t\right)
$$

where $K_{d}, M_{d}$ are stiffness of the derrick cable and mass oftraveling block. $\mathrm{L}_{1}$ is the drill-collar section length and $\mathrm{L}$ is thelength of the drill-pipe section.

The mode shapes are solved from the free vibration equation by the variable separation technique which can be found in most vibration texts. Then substituting Eq.(8) into (6) can reduce the partial differential equation into the following ordinary differential equations.

$$
\ddot{\mathbf{p}}(\mathbf{t})+\Xi \dot{\mathbf{p}}(\mathbf{t})+\boldsymbol{\Omega}^{2} \mathbf{p}(\mathbf{t})=\tau_{1} \frac{\partial u_{b}}{\partial t}+\tau_{2} \frac{\partial^{2} \boldsymbol{u}_{\boldsymbol{b}}}{\partial t^{2}}(9)
$$

where $\mathbf{p}(\mathbf{t})$, is the column vector, and $\boldsymbol{\Xi}, \boldsymbol{\Omega}$ are matrices with the entries as below.

$$
\begin{gathered}
\Xi_{k j}=-\frac{\gamma}{\rho A} \delta_{k j} ; \quad \Omega_{k j}^{2}=\frac{E \int_{0}^{L} X_{k}(x) X_{j}^{\prime \prime}(x) d x}{\rho \int_{0}^{L} X_{k}^{2}(x) d x} \\
\tau_{k 1}=-\frac{\gamma \int_{0}^{L} X_{k}(x) d x}{\rho A \int_{0}^{L} X_{k}^{2}(x) d x} ; \quad \tau_{2 k}=-\frac{\int_{0}^{L} X_{k}(x) d x}{\int_{0}^{L} X_{k}^{2}(x) d x}
\end{gathered}
$$

The orthogonality of the mode shapes have been used in in reaching the above. The torsional vibration can also be derived in a similar way following the steps above.

\section{Stress spectrums}

In general the drill string is under a plane stress status with the largest shear stress at the most outside part under the axial and torsional vibration. However, we start our discussion with the 3 dimensions for generality by assuming stresses exist on all three planes as shown in Fig. 2. Thenthe stress tensor is represented as.

$$
\sigma(x, t)=\left[\begin{array}{lll}
\sigma_{x x} & \sigma_{x y} & \sigma_{x z} \\
\sigma_{y x} & \sigma_{y y} & \sigma_{y z} \\
\sigma_{z x} & \sigma_{z y} & \sigma_{z z}
\end{array}\right]
$$




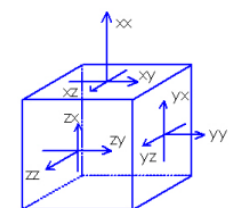

(a)

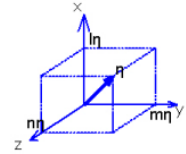

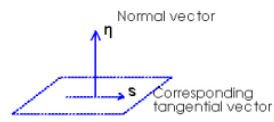

Figure 2. Stress components

For steel drill strings, the above matrix is symmetric; therefore only 6 components are independent which are $\sigma_{\mathrm{xx}}, \sigma_{\mathrm{yy}}, \sigma_{\mathrm{zz}}, \sigma_{\mathrm{xy}}, \sigma_{\mathrm{yz}}, \sigma_{\mathrm{zx}}$. Then the equivalent maximum shear stress is computed through the following equation.

$$
\begin{gathered}
\sigma_{e q}=\left(l_{\eta}^{2}-l_{s}^{2}\right) \sigma_{x x}+\left(m_{\eta}^{2}-m_{s}^{2}\right) \sigma_{y y}+\left(n_{\eta}^{2}-n_{s}^{2}\right) \sigma_{z z} \\
+2\left(l_{\eta} m_{\eta}-l_{\eta} m_{s}\right) \sigma_{x y}+2\left(l_{\eta} n_{\eta}-l_{\eta} n_{s}\right) \sigma_{x z} \\
+2\left(m_{\eta} n_{\eta}-m_{\eta} n_{s}\right) \sigma_{y z}(11)
\end{gathered}
$$

Where $l_{\eta}, m_{\eta}$ andn $n_{\eta}$ are the directional cosines of the vector normal to the critical plane and $l_{s}, m_{s}$ and $n_{s}$ are those of the vector tangential to it as shown in Fig.2 (b) and (c). The tangential vectors $\vec{s}$ will be found by simulation.

If the PSD of the randominput is known, then the PSD of the general axial coordinates $(p(t))$ can be computed through the transfer function of Eq. 8.Then the PSD of the physical coordinates $(\mathrm{u}(\mathrm{t})$ and $\Phi(\mathrm{t}))$ can be obtained as well.Then based on $\sigma_{\text {axial }}=\mathrm{E}(\partial \mathrm{u} / \partial \mathrm{x}) ; \sigma_{\text {shear }}=$ $\mathrm{GR}(\partial \Phi / \partial \mathrm{x})$, the PSD of the stresses can be found which will be used for fatigue prediction in following sections.

\section{Fatigue predictions}

First, the S-N curve of the drill string material is represented as

$$
N(s) s^{b}=c
$$

where $N$ and $s$ are the cycle to failure and the stress amplitude. B and c are positive constants estimated from material experimental test.

The fatigue life is defined as

$$
T=\frac{1}{E[D]}
$$

where $T$ and $E(D)$ are the fatigue life of the drill string and the fatigue damage intensity defined in [17] and given below.

$$
\begin{aligned}
E[D] & =\frac{v_{p}}{c} m_{0}^{\frac{b}{2}}\left[D_{1} Q^{b} \Gamma(1+b)\right] \\
& +2^{\frac{b}{2}} \Gamma\left(1+\frac{b}{2}\right)\left(D_{2}|R|^{b}+D_{3}\right.
\end{aligned}
$$

The parameters used in this equation are as below.

$$
v_{p}=\frac{1}{2 \pi} \sqrt{\frac{m_{4}}{m_{2}}} ; D_{1}=\frac{2\left(x_{m}-\alpha_{2}^{2}\right)}{1+\alpha_{2}^{2}} ;
$$

$$
\begin{gathered}
D_{2}=\frac{1-\alpha_{2}-D_{1}+D_{1}^{2}}{1-R} ; D_{3}=1-D_{1}-D_{2} \\
\alpha_{2}=\frac{m_{2}}{\sqrt{m_{0} m_{4}}} ; Q=\frac{1.25\left(\alpha_{2}-D_{3}-D_{2} R\right.}{D_{1}} ;
\end{gathered}
$$

In those equations, $\mathrm{m}_{\mathrm{n}}$ are the so-called spectrum moment and $\Gamma$ is the Gamma function.

\section{Simulation examples}

For a drill string with the parameters are given in table 1 and the excitations are given in table 2.The S-N curve is

\begin{tabular}{|c|c|c|c|}
\hline Parameter & Collar O.D & Collar I.D & Pipe O.D \\
\hline values & $0.1651[\mathrm{~m}]$ & $0.0572[\mathrm{~m}]$ & $0.114[\mathrm{~m}]$ \\
\hline Parameter & $L_{1}$ & $L$ & $\mathrm{~N}$ \\
\hline values & $200[\mathrm{~m}]$ & $2500[\mathrm{~m}]$ & $1000[\mathrm{rpm}]$ \\
\hline Parameter & $F_{h}$ & $\mathrm{E}$ & $\mathrm{f}$ \\
\hline values & $7 \times 10^{5}[\mathrm{~N}]$ & $\begin{array}{l}2.07 \\
\times 10^{10}\left[\mathrm{~N} / \mathrm{m}^{2}\right] \\
\end{array}$ & $1000[\mathrm{~Hz}]$ \\
\hline Parameter & Pipe I.D & $A_{1}$ & $A_{2}$ \\
\hline values & $0.0972[\mathrm{~m}]$ & $0.0188\left[\mathrm{~m}^{2}\right]$ & $0.0028\left[\mathrm{~m}^{2}\right]$ \\
\hline Parameter & $W_{S}$ & $\rho$ & $\rho_{m}$ \\
\hline values & $1 \times 10^{5}[\mathrm{~N}]$ & $\begin{array}{l}7.89 \\
\times 10^{3} \mathrm{~kg} / \mathrm{m}^{3} \\
\end{array}$ & $\begin{array}{l}1.5 \times \\
10^{3}\left[\mathrm{~kg} / \mathrm{m}^{3}\right]\end{array}$ \\
\hline Parameter & $\gamma_{1}$ & $\gamma_{2}$ & $\mathrm{~g}$ \\
\hline values & $239.4\left[\mathrm{Ns} / \mathrm{m}^{2}\right]$ & $33.5\left[\mathrm{Ns} / \mathrm{m}^{2}\right]$ & $9.81\left[\mathrm{~m} / \mathrm{s}^{2}\right]$ \\
\hline
\end{tabular}
taken from [3] as

$\log _{10} N=14.8-3.47 \log _{10} S_{r}-1.65 \times 10^{5} S_{m}^{2} \quad(15)$

The S-N curves for different $S_{m}$ is shown in Fig.3 and the $S_{m}$ for different positions is shown in Fig. 4 .

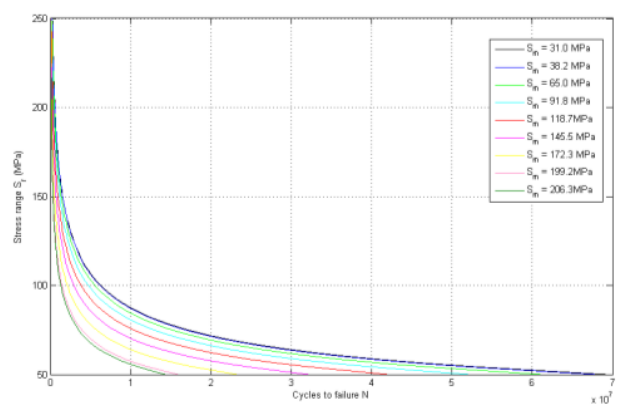

Figure 3. S-N curves with different mean stress

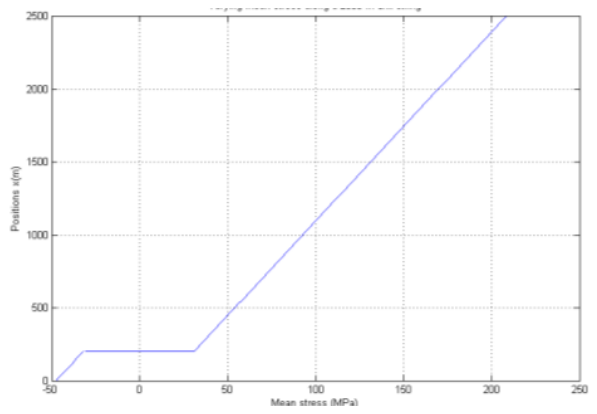

Figure 4. Varying means stress

Table 1. Parameters of simulation 
Table 2. Excitation parameters

\begin{tabular}{|l|l|l|l|l|l|l|}
\hline \multicolumn{2}{|l|}{ Parameter } & $A_{d}(A)$ & $A_{d}(T)$ & $A_{w}(A)$ & $A_{w}(T)$ \\
\hline No.1 & 3 & 150 & 0 & 0 \\
\hline No.2 & 3 & 150 & 0.3 & 15 & & \\
\hline No.3 & 3 & 150 & 0.6 & 30 & & \\
\hline No.4 & 0 & 0 & 0.3 & 15 & & \\
\hline
\end{tabular}

The No.1 excitation contains only deterministic input; while No.4 contains only random. The simulation results for these two cases are shown in Fig.5 and 6.

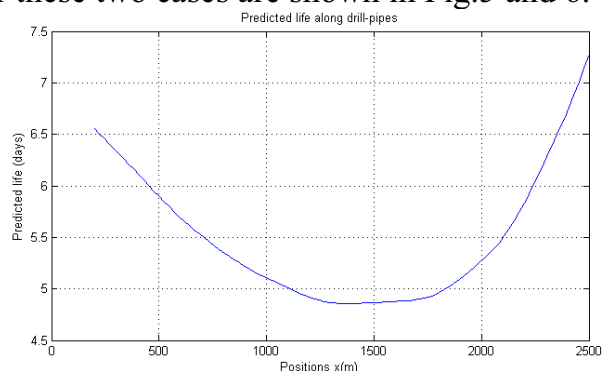

Figure 5. Predicted life under excitation(No.1)
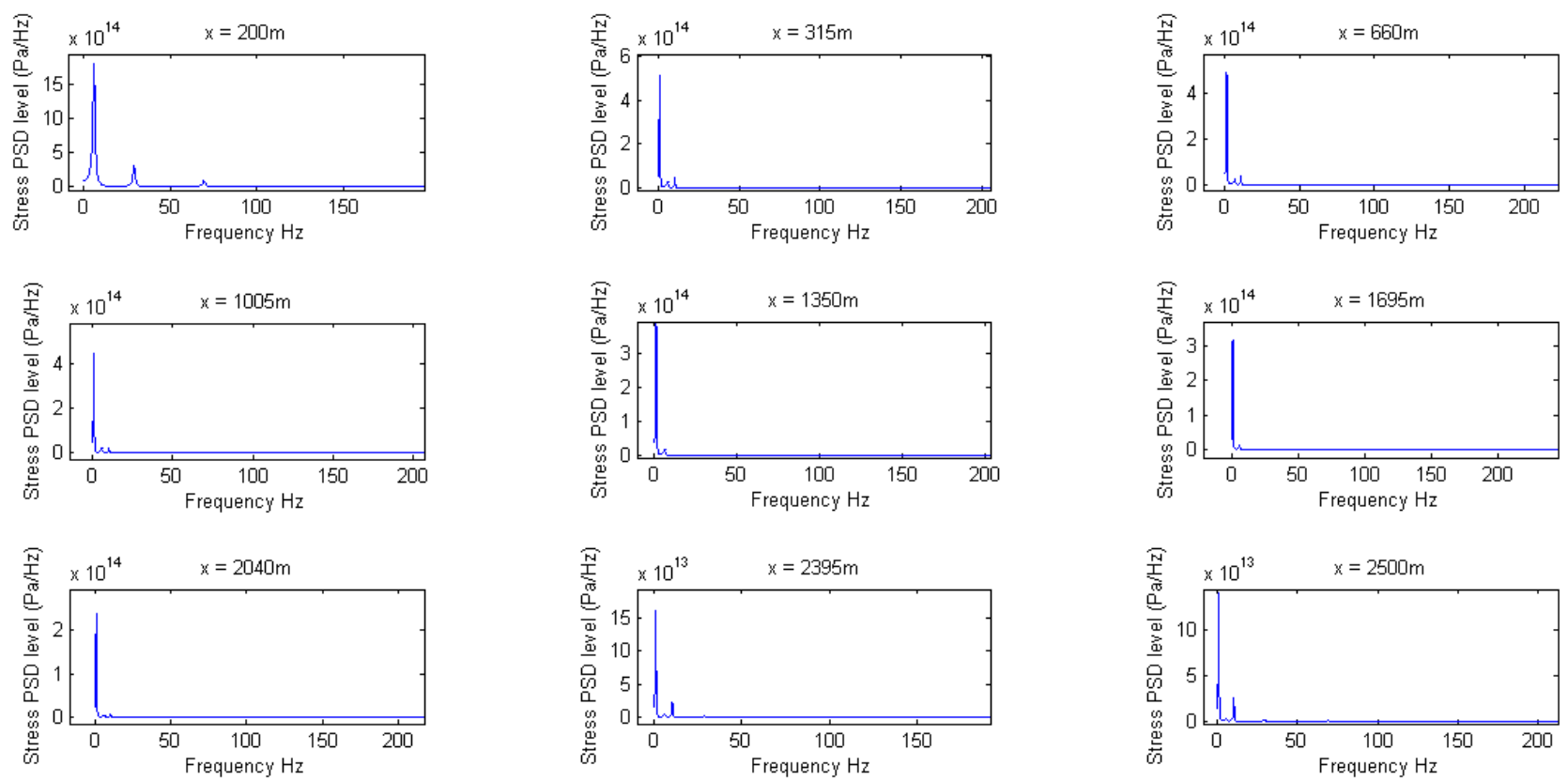

Figure7. PSD of equivalent stresses

random excitation is on the part near the drill collar(the most left part of the curve). To understand the random effect we computed the PSD of the equivalent stress at 9 different positions and shown in Fig.7. Clearly first position $(x=200 \mathrm{~m})$ has the largestvalue of the first frequency peak which means the most energy transferred to this part of the drill string. If we compare the effect of different intensities of the random excitation on the fatigue, Excitations No.1, No.2 and No.3 have the same level of deterministic excitation, but with different random excitations. The fatigue life predicted is shown in Fig. 8. It is clearthat the stronger the random excitation, the shorter the fatigue life of the drill-string at any position. This makes sense because stronger random excitation causes more severe vibrationand does more harm to the fatigue life of the drill-string.

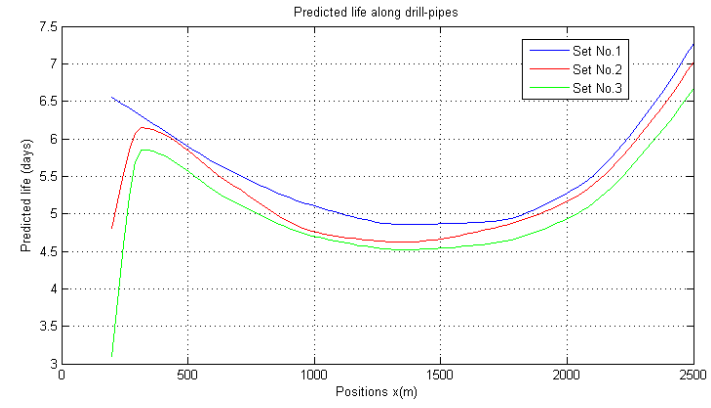

Figure 8. Predicted failure life.

\section{Conclusions}


A vibration model considering the axial and torsional vibrations of a drill-string is first developed. Then a combined deterministic and random excitation at the bitrock interaction is assumed and the vibration response is obtained. Based on the vibration model, a spectral method is applied to estimate the effect of the vibration of the drill-string, including both deterministic and random. The ultimate purpose of this paper is to develop a feasible spectral method of fatigue life estimation to account for the vibration's influence on the fatigue of the drill-string.

\section{References}

1. W. Bachman, World Oil.132, 104 (1951)

2. R. P. Morgan, M. J. Robin, A method for the investigation of fatigue strength in seamless drillpipe. (1969)

3. G. Y. Grondin, G. L. Kulak,Fatigue of drill pipe. Department of Civil Engineering, University of Alberta (Technical report) (1991)

4. K. Sobczyk, Jr, B. Spencer, Random fatigue: from data to theory(Academic Press, 1992)

5. O. Vaisberg, O. Vincke, G. Perrin, J. Sarda, Oil \& Gas Science and Technology, 57, 7 (2002).

6. A. Lubinski, J. of Petrol. Tech.13(2),175(1961)

7. J. E. Hansford, A. Lubinski, J. Petro. Tech., 18, $359(1966)$
8. J. Wu, SPE Eastern Regional Meeting,SPE 37353,195,(1996).

9. J. Wu, Oil and Gas Journal, 95, 5(1997).

10. M. Patel, M. Vaz, Proceedings of the Institution of Mechanical Engineers, Part E: Journal of Process Mechanical Engineering, 209(1), 17(1995).

11. J. Grzelak, T. Lagoda, E. Macha Materialwissenscha ftund Werks to fftechnik, 22(3), 85 (1991)

12. Dirlik, T. "Application of computers in fatigue analysis" $\mathrm{PhD}$ thesis, University of Warwick,(1985)

13. S. S. Rao, Vibration of continuous systems(John Wiley \& Sons2007).

14. M. Vaz, M. Patel, Engineering structures, 17(6), 437(1995)

15. L. D .Lutes, S. Sarkani, Random vibrations: analysis of structural and mechanical systems( ButterworthHeinemann2004)

16. F. Deily, D. Dareing, G. Paff, J. Ortloff, J. Manufacturing Science and Engineering, 90(2), 217(1968)

17. A. Nieslonyand, E. Macha, Spectral method in multiaxial random fatigue, Springer, (2007)

18. D. Benasciutti, R. Tovo, International Journal of fatigue, 27,8, 867-877(2005).

19. D. Benasciutti, Fatigue analysis of random loadings. $\mathrm{PhD}$ University of Ferrara, Department of Engineering(2004)

20. J. W. Miles, Journal of the Aeronautical Sciences, 21, $11,753-762$ ( 2012). 